\title{
An Integrative Framework For E-Business Information System Development
}

\author{
S.M.R. Nasserzadeh, (Email: reza.nasserzadeh@gmail.com), University of Tehran, Iran \\ Babak Sohrabi, (Email: bsohrabi@ut.ac.ir), University of Tehran, Iran \\ Mohammad Mosakhani, University of Tehran, Iran
}

\begin{abstract}
The advent of networked economy calls for new understanding of business, and it is evidenced by the visible trend of traditional businesses either migrating to e-business or expanding to embrace electronic commerce. The development of new business models supported by information technology has become an important issue in the business community. This paper first describes different kinds of information systems and their criteria, e-business information system framework and then map IS criteria into the EBIS criteria to extend the former EBIS framework and to reach an integrative framework which fills the gap between IS categories and EBIS. The mapping process was done by academics and managers of top 50 firms in Iran. Consequently the paper discusses the roadmap guiding information system planners and designers.
\end{abstract}

Key Words: e-business, information systems, integrative framework

\section{Introduction}

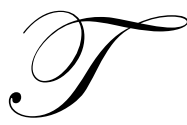

he purpose of this article is to map the ten IS criteria (Palvia's model) into the three EBIS criteria in order to develop a roadmap for information system planners and particularly information system designers. Researchers, in their effort to improve e-business information system planning, have developed an EBIS framework for IS planners. A major objective of the EBIS framework is identifying key factors that determine the information requirements of e-business. The classification framework clearly delineates how each of these models varies on its information management requirements (Pant \& Ravichandran, 2001). It is required to provide a roadmap for IS designers who organize the structure of the IS after planners have done their job (Neuman, 1994).

Although information systems of some form or another have been around since the beginning of time, information technology (IT) is a relative newcomer to the scene. The facilities provided by such technology have had a major impact on individuals, organizations and society. There are few companies that can afford the luxury of ignoring IT and few individuals who would prefer to be without it despite its occasional frustrations and the fears it sometimes invokes (Galliers \& Liedner, 2003). The term "business model" is widely used in the business literature. Some refer business models to cases or scenarios (Wise and Baumgartner, 1999), and others refer a business model to a set of components of management, such as culture, governance, decision making structures, etc. (Hoerl, 1999). Since the theme of e-business is the business supported by information technology, the boundary between business modeling and information system modeling is often blurred and few precise definitions of business model or systematic discussions on business models can be found in the literature. In this study, we focus e-business models particularly issues which are related to their information systems and expanding the planning of e-business information systems.

Hence, it is important for organizations to carefully plan for and architect e-business systems, understanding that the nature of these systems is quite different from those of traditional interorganizational information systems. However, limited research has been done in the area of e-business systems planning. Existing IS planning models were developed prior to the advent of the Internet (Pant \& Ravichandran, 2001). 
In this article EBIS criteria which are based on internet capabilities are corresponded to IS criteria. What is required is a guideline which facilitates thorough IS planning and designing for e-business models, the dominating models of nowadays business. Drawing from the survey we categorized the Palvia's 10 IS criteria according to the EBIS three criteria. Therefore it is possible now to classify e-business models according to EBIS framework and further determine the kinds of information system models they need.

In section 1 we briefly review IS definitions and classifications, EBIS and its dimensions are discussed in section two. The following section includes our integrative framework, research methodology and discussion of the results. And the final section encompasses conclusion and future research.

\section{What Is An IS?}

An information system (IS) collects, processes, stores, analyzes, and disseminates information for specific purpose. Like any other system, an information system includes inputs (data, instructions) and outputs (reports, calculations). It processes the inputs by using technology such as computers and produces outputs that are sent to users or to other systems by means of electronic networks. A feedback mechanism that controls the operation may be included. Like any other system, an information system also includes people, procedures, and physical facilities, and it operates within an environment. An information system is not necessarily computerized, although most of them are. Information systems are usually connected by means of electronic networks. The connecting networks can be wireline and/or wireless. Information systems can connect an entire organization, or even multiple organizations. If the entire company is networked and people can communicate with each other and access information throughout the organization, the arrangement is known as an enterprisewide information system. An interorganizational information system, such as FedExNet, involves information flow among two or more organizations, and is used primarily in e-business applications (Turban et al., 2003).

Another definition for IS includes all systems used to create, store, exchange, manage and use information in its various forms inside a firm and across its borders (Osterwalder, 2001). Information systems are made out of components that can be assembled in many different configurations, resulting in a variety of information systems and applications (Turban et al., 2003).

\subsection{Classification And Evolution Of Information Systems}

According to Turban researches information systems can be classified in several alternative ways. In this paper we use 3 kinds of classifications which are a) classification by organizational levels b) classification by type of support provided and c) classification according to evolution. The first two were proposed by Turban and the third was mentioned by Palvia, Palvia \& Zigli.

\section{A) Classification By Organizational Levels}

Organizations are made up of components such as divisions, departments, and work units, organized in hierarchical levels. For example most organizations have functional departments, such as production and accounting, which report to the division head. The divisions report to the corporate headquarters. Thus we can find information systems built for headquarters, for divisions, for functional departments, for operating units, and even for individual employees. Such systems can stand alone, but usually they are interconnected.

Typical information systems that follow the organizational structure are functional (departmental), enterprisewide, and interorganizational. These systems are organized in hierarchy in which each higher level system consists of several (even many) systems from the level below it, as shown in Figure 1. As can be seen in the figure, a departmental system supports the functional areas in each company. At a higher level, the enterprise system supports the entire company, and interorganizational systems connect different companies. (Turban et al., 2003) 


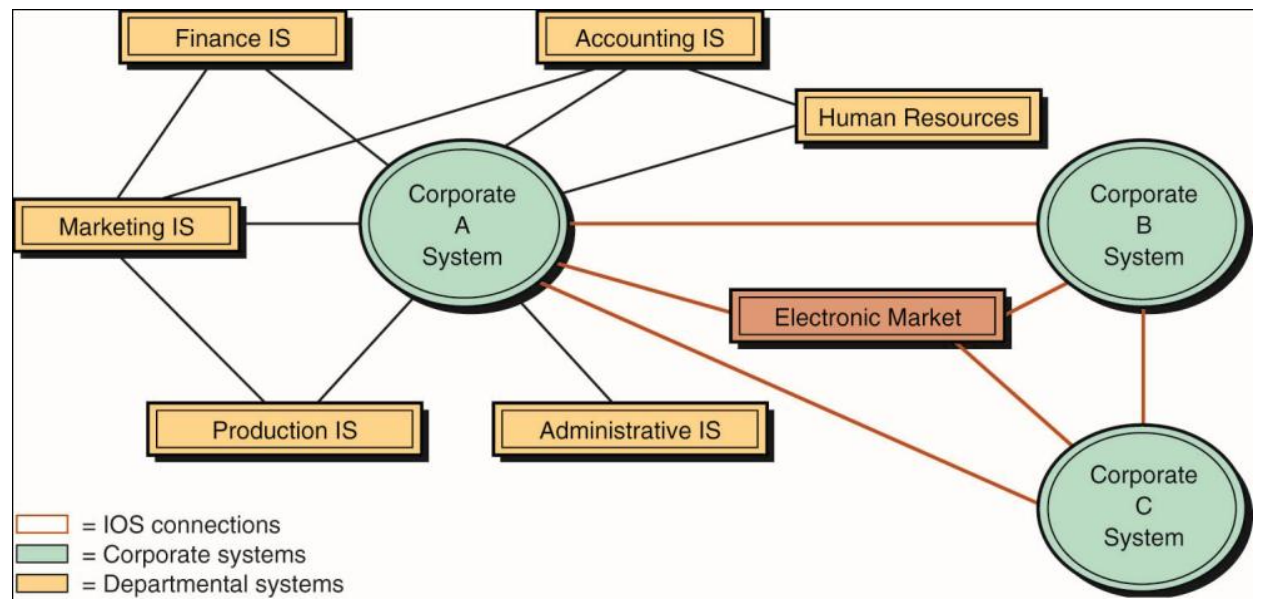

Figure 1. Departmental, corporate, and interorganizational information systems

\section{B) Classification By The Type Of Support Provided}

Another way to classify information systems is according to the type of support they provide, regardless of the functional area. For example, an information system can support office workers in almost any functional area. Likewise, managers working from various geographical locations can be supported by a computerized decision making system. The main types of support subsystems are listed in Table 1 together with a brief description of each. (Turban et al., 2003)

\begin{tabular}{|c|c|c|}
\hline System & $\begin{array}{l}\text { Employees } \\
\text { Supported }\end{array}$ & Description \\
\hline $\begin{array}{l}\text { Transaction processing } \\
\text { system (TPS) }\end{array}$ & All employees & $\begin{array}{c}\text { Processes an organization's basic business transactions (e.g., } \\
\text { purchasing, billing, and payroll). }\end{array}$ \\
\hline $\begin{array}{l}\text { Management information } \\
\text { system (MIS) }\end{array}$ & All employees & $\begin{array}{l}\text { Provides routine information for planning, organizing, and } \\
\text { controlling operations in functional areas. }\end{array}$ \\
\hline $\begin{array}{l}\text { Decision support system } \\
\text { (DSS) }\end{array}$ & $\begin{array}{l}\text { Decision makers, } \\
\text { managers }\end{array}$ & $\begin{array}{c}\text { Combines models and data to solve semistructured problems with } \\
\text { extensive user involvement. }\end{array}$ \\
\hline $\begin{array}{l}\text { Executive support system } \\
\text { (ESS) }\end{array}$ & $\begin{array}{c}\text { Executives, senior } \\
\text { managers }\end{array}$ & Supports decision of top managers \\
\hline
\end{tabular}

Table 1. Main types of IT support systems

\section{C) Classification According To Evolution}

In the past decade, information systems have undergone a steady evolution. As a consequence, information systems applications can be categorized, in order of evolution, into transaction processing system (TPS), management information system (MIS), decision support system (DSS), and executive information system (EIS). Each of these definitions interpreted in a narrow sense in Table 1. This classification is in accordance with Anthony's framework (Anthony, 1965). Gorry and Morton (1971) classified information systems for operational control, management control, and strategic planning. Their classification with some modification is shown in Figure 2. (Palvia, Palvia \& Zigli, 1995; McFarlan, 1983) 


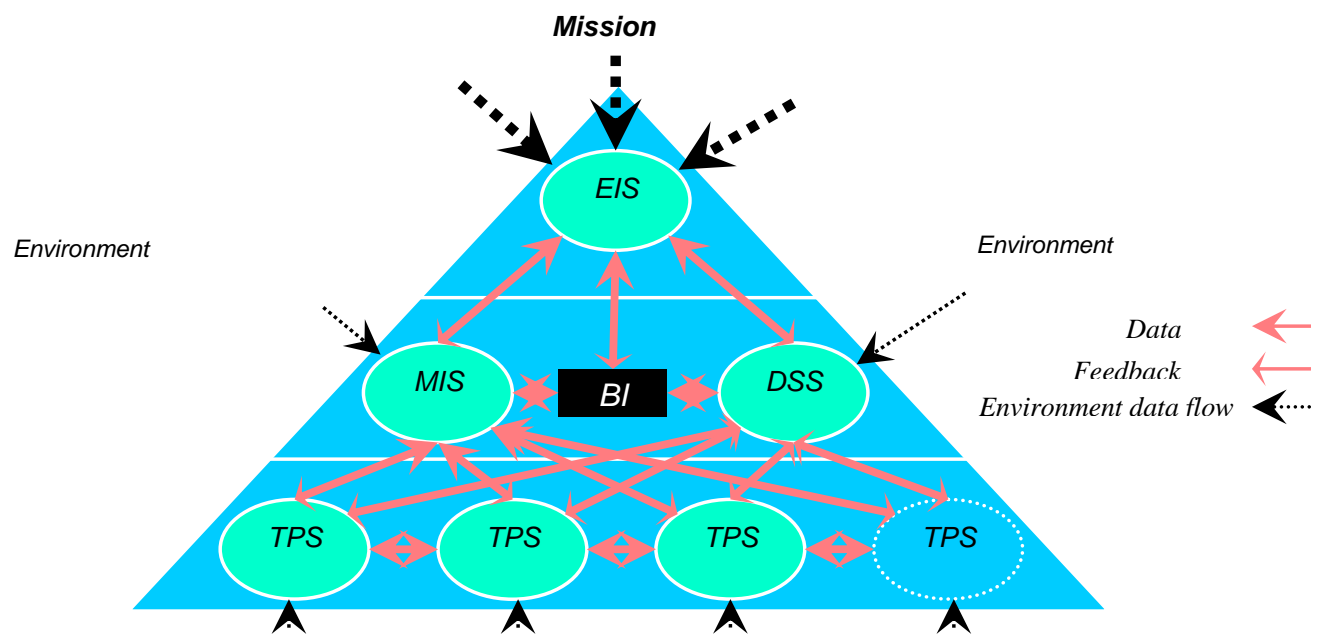

Figure 2. Modified classification of Gorry \& Morton

This figure is a schematic model of organizational information systems. It demonstrates the position of information systems in addition to kinds and density of information flow between them. The model is an integration of Anthony and Palvia's models. As shown in the model, environmental data is much more important in EIS than MIS based on Palvia's assertion. According to evolutionary trend, TPS/EDP was first designed to process the functional data which are almost internal. In the next stage of information systems development, MIS was established to handle middle level managers' needs. MIS is fed data which have been gathered by TPS/EDP and a little environmental data. Finally DSS and EIS evolved to assist top level managers resolve semi-structured and unstructured problems. These systems are highly environment based.

They compared these three IS on the criteria of source, scope, level of aggregation, time horizon, currency, required accuracy, and frequency of use. Palvia, Palvia \& Zigli in their research added three more criteria including problem structure, use of models, and batch versus interactive to compare and classify four types of information systems (TPS, MIS, DSS and EIS). Their comparison is provided in Figure 3. Further, these four types of information systems are clearly evolutionary systems, that is, MIS used TPS as a base, then MIS provided the base for DSS (plus the capability for iterative and interactive computing and modeling), and finally EIS is using DSS as a base. (Palvia, Palvia \& Zigli, 1995)

\section{What Is An E-Business Information System (EBIS)?}

The use of the Internet technologies to manage information is a substantial improvement on traditional information systems and conventional uses of the Web (Applegate, 1995; Hsu and Pant, 2000; Venkatraman, 1994). The use of the Internet for enterprise applications has created a new breed of information systems called the ebusiness information systems (EBIS). E-business information systems are computer applications that use the Internet technology, its universal connectivity and the capabilities of the Web browser to integrate business processes within and beyond an enterprise. It can be inferred that internet has changed the platform on which information systems are embedded. It opened up a new course through which existing information systems should migrate to approach their main positions in a newly networked economy (Pant \& Ravichandran, 2001).

E-business information systems allow transactions to be conducted in an integrated and enlarged information space by removing constraints imposed by diverse computing platforms, networks, and applications (Isakowitz and Fabio, 1998; Lederer and Sethi, 1998). The Internet and the Web technologies not only allow automation of inter-organizational processes, but also allow individual users to interact with organizational information systems in novel ways and at a very low cost (Pant \& Ravichandran, 2001). 


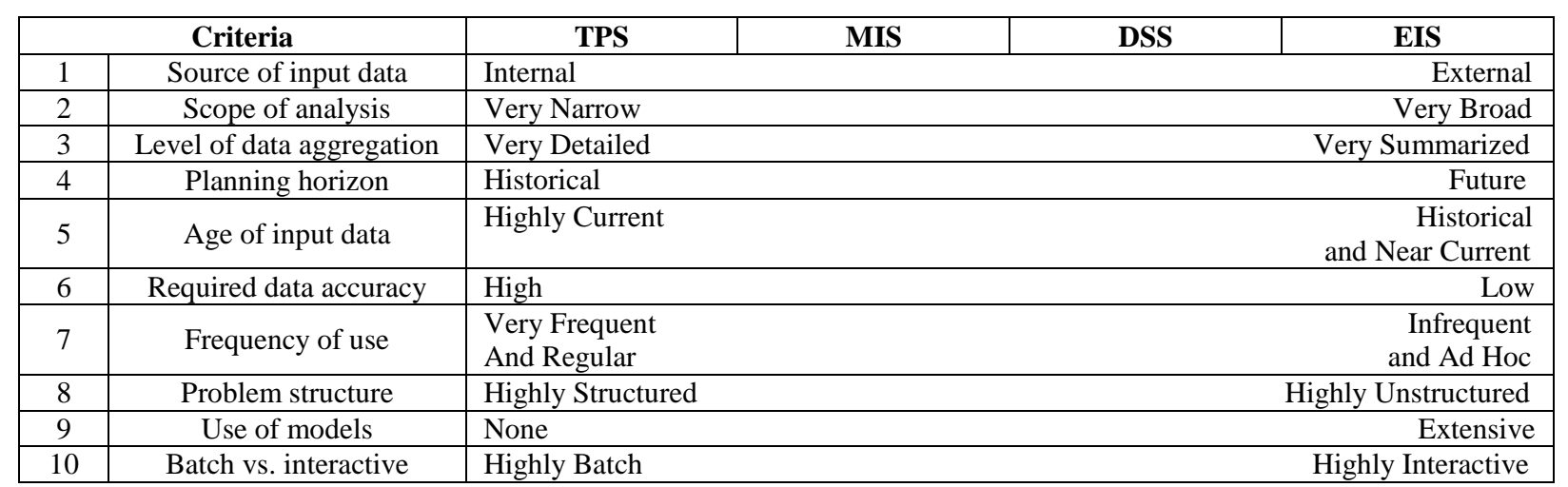

Figure 3. Palvia \& Zigli comparison model

\subsection{EBIS Dimensions}

EBIS allows organizations to explicitly focus on the unique information management needs faced by ebusinesses. Theoretically, information integration, timeliness of information exchange and creating a community of users are identified as important axes on which e-business needs to position its information architecture requirements(Pant \& Ravichandran, 2001).

As a theoretical basis for the first criterion (information integration), the transaction cost theory explains the economics of information and information systems. The originator of this theory, Ronald Coase (1937), argued that, contrary to assumptions that transactions through exchange mechanisms are homogeneous, real-life transactions are more complex and involve transaction costs. It is suggested that integration of organizational and inter-organizational processes (including customer processes) significantly reduces transaction costs (Hoffman and Hsu, 1993). The potential to lower transaction costs by using information technology presents a significant strategic opportunity that organizations must exploit to succeed in the new economy. In fact, e-businesses are attempting to use the Internet to seamlessly integrate enterprise systems, databases, and workflows across organizational boundaries and planning frameworks (Pant \& Ravichandran, 2001).

Information exchange is critical for any business model since information is an agent of coordination and control and serves as the glue that holds together organizations, franchises, supply chains and distribution channels. Along with material and other resource flows, information flows must also be handled effectively in any organization. Whether information is used for control and coordination or sold as a product, its value is dependent on its half-life. Half-life of information refers to how quickly the information becomes dated or obsolete; some information has a higher half-life, while others have a very short half-life. The half-life of information is a function of its timely dissemination and sharing. Consequently, how quickly information needs to be exchanged between processes becomes an important information infrastructure design issue (Pant \& Ravichandran, 2001).

The third theoretical underpinning for creating a community of users comes from the economic concept of network externalities or network effects. This effect explains how the value of a product or service increases as the number of users of the product or the service increases. Metcalf stated this law as "the usefulness, or utility, of a network equals the square of the number of users" (Downes and Chunka, 1998). In general, a higher value will be achieved by e-business systems that create global communities of customers, business partners and suppliers.

\section{The Need For An Integrative Framework}

As mentioned above in the previous section, earlier researches are either on information systems or ebusiness information systems at macro level analysis. There is no link between information system categories and ebusiness information system specifications as was introduced in EBIS framework. Utilizing EBIS, we can only 
classify e-business models according to the information management needs and give planners an opportunity to plan on a general situation for e-business information system. But IS designers need to have a roadmap to know what information systems are needed for e-business models according to the EBIS framework. Thus in this paper we try to map Palvia's 10 criteria of information systems to EBIS three axes in order to reach an integrative framework which fills the gap between IS categories and EBIS, and it can be used by designers as a roadmap for information system design (ISD).

\subsection{Research Methodology}

\subsubsection{Sample And Survey Instrument}

The purpose of this study is to analyze the correspondence of Palvia's ten criteria to EBIS three criteria.

To understand the correspondence mentioned above, we conducted a mail survey among Iranian university professors and researchers and also information system managers of the top 50 firms according to Iran Stock Market. The sampling frame included 50 professors and researchers whose field of research was information systems, e-business models or both of them, the other 50 were information related managers and experts of the top 50 Iranian firms which were chosen based on the higher frequency in the past five years(from the year 2001 to 2006). The sample in total resulted in a list of 100 persons.

A mail survey was chosen to create a large enough sample of the experts and also to reach those experts who do not live in the same place. Questionnaires were mailed with addressed, stamped return envelopes, a reply coupon to the draw, and a cover letter. From a sample of 100 mailed questionnaires 63 were returned, resulting in a response rate of $63 \%$.

The questionnaire included 10 questions according to the ten criteria of Palvia's model. Each question contained one of the 10 criteria (source of input data, scope of analysis, level of data aggregation, planning horizon, age of input data, required data accuracy, frequency of use, problem structure, use of model, batch vs. interactive) and asked the respondents whether the IS criterion corresponded to one of the 3 constructs of EBIS (information integration, timeliness of information exchange, creating a community of users) or not. Data collected with this instrument was analyzed and validated through pretesting and reliability tests. The reliability of the questionnaire was affirmed by a Cronbach's standardized item alpha reliability coefficient of $84 \%$. Altogether the questionnaire was recognized as reliable one for this study.

\subsubsection{Results \& Statistical Analysis}

The results are shown in Table 3. According to the respondents, source of input data indicates community with a frequency of 44, scope of analysis indicates integration with a frequency of 51; level of data aggregation indicates integration with a frequency of 49 . Interestingly, planning horizon gained a point of 53, indicating none of the three constructs of EBIS. Age of input data with a frequency of 42 indicates timeliness. Required data accuracy indicates integration with 48 points. Frequency of use is the indicator of timeliness with a frequency of 52. Problem structure and use of model both indicate none of the EBIS constructs with the points of 51 and 50 respectively. Finally batch vs. interactive indicates timeliness with a frequency of 49 .

\begin{tabular}{|l|c|c|c|c|}
\hline & Timeliness & Integration & Community & None \\
\hline 1. Source of input data & 2 & 3 & $\mathbf{4 4}$ & 11 \\
\hline 2. Scope of analysis & 4 & $\mathbf{5 1}$ & 2 & 4 \\
\hline 3. Level of data aggregation & 5 & $\mathbf{4 9}$ & 4 & 3 \\
\hline 4. Planning horizon & 4 & 3 & 1 & $\mathbf{5 3}$ \\
\hline 5. Age of input data & $\mathbf{4 2}$ & 4 & 5 & 7 \\
\hline 6. Required data accuracy & 5 & $\mathbf{4 8}$ & 4 & 2 \\
\hline 7. Frequency of use & $\mathbf{5 2}$ & 3 & 2 & 4 \\
\hline 8. Problem analysis & 4 & 5 & 2 & $\mathbf{5 1}$ \\
\hline 9. Use of model & 0 & 6 & $\mathbf{5 0}$ & 6 \\
\hline 10. Batch vs. interactive & $\mathbf{4 9}$ & 3 & 2 & \\
\hline
\end{tabular}




\subsection{Discussion}

The results categorize age of input data, frequency of use and batch vs. interactive criteria in timeliness. Now designers have the measure to consider how they can apply the timeliness of information exchange to the design of an IS. When the age of input data is historical it is easier to reach timeliness through EIS like information systems and when the age is highly current it is recommended to utilize TPS like information systems to fulfill the purpose. And if the age is in between, designers can use MIS or DSS like systems. So designers can set timeliness of information exchange through these three IS criteria.

Scope of analysis, level of data aggregation and required data accuracy denote information integration. For instance, when level of data aggregation is very detailed, in order to have more information integration, designing EDP like information system is proposed. On the contrary, when level of data aggregation is very summarized, utilizing EIS like information systems is recommended.

Source of input data indicates the community. That is, the internal and external communities provide the needed data. Thus it should be considered that if e-business information system needs internal data, it is better to design an EDP like information system to satisfy the internal community creation. On the other hand if the ebusiness relies heavily on external data for its information needs, the design and use of an information system which is more dependent on external data such as ESS is proposed.

Surprisingly, planning horizon, problem structure and use of models indicate none of the EBIS criteria. Nature of these three remaining criteria is environmental. Planning horizon is related to organization or business environment requirements. Problem structure shows the degree of environmental problems complexity and use of models is applicable to aforementioned problems. E-business activity environment can be categorized in competitive environment and macro environment which include all the external forces having impact on the firm performance (Afuah \& Tucci, 2003). So it can be inferred from the results that EBIS framework need another axe which is ebusiness activity environment which defines the field of e-business model activities, its environment and problem structures affect the e-business model.
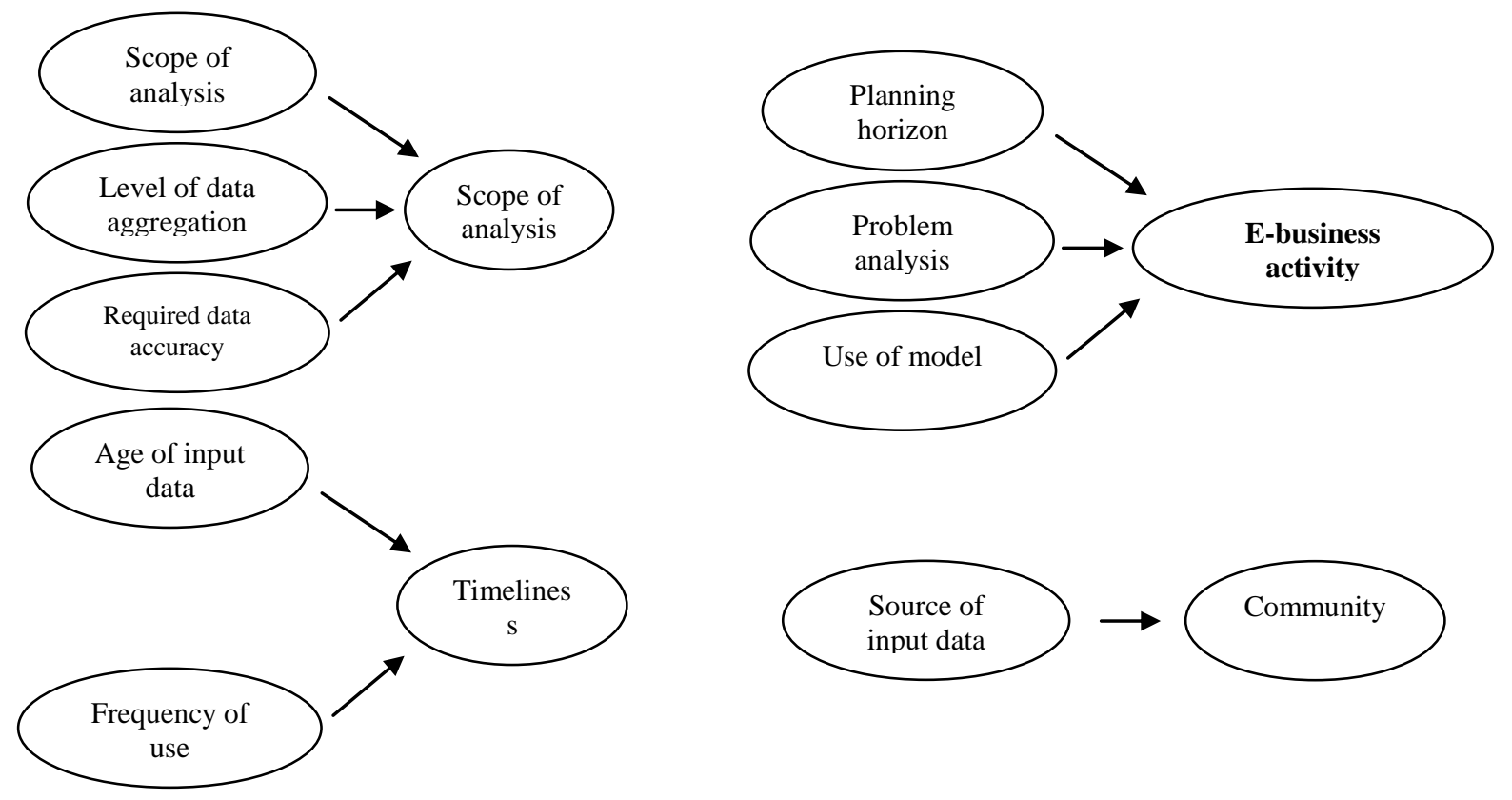


\section{Conclusion}

In this paper a roadmap for information system designers is established and the EBIS framework is extended to another four stakeholders (owners, designers, builders, and subcontractors) as mentioned in the future research of Somendra and Ravichanran article.

Researchers are encouraged enthusiastically to evaluate the extended framework and refine it more on its dimensions. Although we have utilized the four main instances of IS applications from Palvia's model, it is suggested that feasibility of putting more instances of information systems (ES, AI, and etc) be taken into account. This study has been done in Iran, thus our integrative framework emerged from Iranian researchers and experts. It is suggested that the mapping process being done in the other countries with other status in information system maturity and business environment. In the next step we want to develop the framework in a more quantitative fashion with fuzzy weights, because not only the boundaries between the constructs of the integrative framework are not crisp but also it is overlapping (Wang, 2001). Doing some field researches in an assorted bunch of organization are recommended to evaluate the practicality of the integrative framework.

In conclusion this study addressed how the overall architecture of e-business systems should be planned and designed. Regarding the mapping process we realized that the EBIS framework needs another axe which is ebusiness activity environment. Besides the research contribution, this extended framework can be used practically by IS planners and designers in the subsequent way:

- $\quad$ Firms will need to identify their e-business model. A firm's e-business model could be one of the many models or, more likely, a combination of two or more of those business models.

- Identification of the business model will lead to positioning the firm on the I-T-C-E axes, which in turn highlights specific information management needs.

- $\quad$ Next, the architecture planners will need to evaluate the benefits and risks of their architectures and then augment their data, process, network, people, time, and motivation issues to respond to requirements made by EBIS on these aspects of their architectures.

- $\quad$ They can decide which IS application (TPS, MIS, DSS, ESS) or combination of them to use in order to satisfy the requirements identified in the third step by matching the EBIS criteria with the IS criteria.

Finally the IS experts and researchers are invited to add their comments related to their business activity environment and their specific industry to the framework and make it more rich.

\section{References}

1. Afuah A, Tucci CL., (2003) Internet business models and strategies, McGraw-Hill/Irwin

2. Anthony R.N, (1965), Planning and Control Systems: A Framework for Analysis, Cambridge MAL Harvard University Press,.

3. Applegate, L.M. (1995), Electronics Commerce: Trends and Opportunities, Harvard Business School Case Series, Case 9-196-004.

4. Coase, R. (1937), The nature of the firm, Economica, No. 4, pp. 386-405. Reprinted in Coase, R. (1988), The Firm, the Market and the Law, University of Chicago Press, Chicago, IL.

5. Downes, L. and Chunka, M. (1998), Killer App., Harvard Business School Press, Boston, MA.

6. Galliers, R.D. Leidner D. E. (2003), Strategic Information Management: Challenges and strategies in managing information systems, Butterworth Heineman,

7. Hoerl, R. (1999), Using an effective business model for group practice management, Healthcare Financial Management, Vol. 53 No. 11, pp. 61-3.

8. Hoffman, W.J. and Hsu, C. (1993), The value of information: an evaluation model for enterprise integration using transaction cost and information requirement s analysis, Selected Essays on Decision Sciences, pp. 119.

9. Hsu, C. and Pant, S. (2000), Innovative Planning for Electronic Commerce and Enterprises: A Reference Model, Kluwer Academic Publishers, Norwall, MA. 
10. Isakowitz, T., Michael B. and Fabio, V. (1998), Web information systems introduction, Communications of the ACM, Vol. 41, pp. 78-80

11. Palvia, P. Palvia, S. Zigli, R., (1995), Strategic Information Systems Managing Information Technology Resources, IGP

12. Lederer, A.L. and Sethi, V. (1989), Pitfalls in planning, Datamation, June 1, pp. 59-62.

13. McFarlan, W. F, \& McKenney, J. L, (1983) Corporate Information Systems Management, Homewood, IL, Irwin,

14. Neuman S, (1994), Strategic Information Systems: Competition Through Information Technologies, Macmillan College Publishing.

15. Osterwalder, A. (2001), An e-Business Model Ontology for the Creation of New Management Software Tools and IS Requirement Engineering, http://inforge.unil.ch/aosterwa

16. Pant, S., Ravichandran, T., (2001), A framework for information systems planning for e-business, Logistics Information Management Volume 14. Number 1/2. pp. 85-98

17. Turban, E., McLean, E., Wetherbe, J. (2003), Information technology for management, Willy

18. Venkatraman, N. (1994), IT-enabled business transformation: from automation to business scope redefinition, Sloan Management Review, Winter, pp. 73-87.

19. Wang, S., (2001), Designing information systems for electronic commerce, Industrial Management \& Data Systems, 101/6 pp. 304 \pm 314

20. Wise, R. and Baumgartner, P. (1999), Go downstream: the new profit imperative in manufacturing, Harvard Business Review, Vol. 77 No. 5, pp. 133-41.

\section{NOTES}


NOTES 